\title{
Effects of levosimendan on mortality in patients with septic shock: systematic review with meta-analysis and trial sequential analysis
}

\author{
Benji Wang ${ }^{1}$, Rujie Chen ${ }^{1}$, Xianyang Guo ${ }^{1}$, Wenwu Zhang ${ }^{1}$, Jianjian Hu ${ }^{1}$, Yuqiang \\ Gong $^{1}$ and Bihuan Cheng ${ }^{1}$ \\ ${ }^{1}$ Department of Critical Care Medicine, The Second Affiliated Hospital and Yuying Children's Hospital of Wenzhou Medical \\ University, Wenzhou 325000, Zhejiang, China
}

Correspondence to: Bihuan Cheng, email: cbihuan@163.com

Keywords: levosimendan, mortality, septic shock, meta-analysis, trial sequential analysis

Received: May 24, $2017 \quad$ Accepted: July 30, $2017 \quad$ Published: August 10, 2017

Copyright: Wang et al. This is an open-access article distributed under the terms of the Creative Commons Attribution License 3.0 (CC BY 3.0), which permits unrestricted use, distribution, and reproduction in any medium, provided the original author and source are credited.

\section{ABSTRACT}

Object: Several studies have investigated a survival benefit for levosimendan treatment in patients with septic shock. However, data are conflicting. We conducted a meta-analysis to evaluate the effect of levosimendan treatment on mortality in patients with septic shock.

Materials and Methods: We searched PubMed, EMBASE and Cochrane Library Databases up to March 27, 2017, without language restrictions. We searched for terms related to septic shock, levosimendan, randomized clinical trial. Randomized controlled trials reported the effect of levosimendan on mortality were included. Moreover, we constructed the trial sequential analysis (TSA) to determine the reliability of the outcomes. Furthermore, secondary outcomes were cardiac index(CI), mean arterial pressure (MAP), blood lactate, norepinephrine dose and length of ICU stay.

Results: Ten studies with a total of $\mathbf{8 1 6}$ patients were included in this metaanalysis. There was no significant difference in the mortality between the levosimendan group and the standard inotropic therapy group $[R R=0.96,95 \%$ CI $(0.81-1.12)$, $\left.I^{2}=0\right]$. However, methods adapted from formal interim monitoring boundaries applied to TSA indicated that the cumulative evidence was unreliable and inconclusive. Blood lactate was significantly reduced in the levosimendan group while there was no difference in MAP, CI, norepinephrine dose and length of ICU stay.

Conclusions: Findings from this meta-analysis demonstrated that levosimendan treatment may not reduce mortality in patients with septic shock. The result remains inclusive and further randomized controlled trials were needed to confirm these conclusions.

\section{INTRODUCTION}

Sepsis is defined as life-threatening organ dysfunction caused by a dysregulated host response to infection. [1] Septic shock is the most severe form of the condition and results in circulatory and metabolic abnormalities [2]. The mortality and morbidity rate of patients with septic shock has remained high $[3,4]$, despite decades of medical advances [5]. Persisting hypotension despite adequate fluid resuscitation is due to a combination of profound vasodilatation, vascular hyporeactivity to catecholamine, and myocardial depression [6]. Cardiovascular dysfunction owing to severe infection is thought to play an important role in sepsis related mortality [7].

Dobutamine is widely acknowledged that can be used in the treatment of septic cardiomyopathy, as international sepsis guidelines recommended [5]. A body of epidemiologic studies have demonstrated that the use of dobutamine increases contractility and cardiac output, but it does not improve microcirculation or peripheral perfusion [8], and even increased the mortality rate [9]. 
Levosimendan is a calcium-sensitizing drug with inotropic, which has been used for treatment of decompensated heart failure [10]. It increases myocardial contractility with vasodilatory properties [11], meanwhile diastolic relaxation is not impaired [12]. Several studies have reported that levosimendan exerts anti-ischemic, anti-inflammatory, and anti-apoptotic properties, thereby affecting important pathways in the pathophysiology of septic shock [13-16]. Furthermore, it also has shown improvements in hemodynamic variables, microcirculatory flow, and renal and hepatic function, as compared with dobutamine [17-19]. A recent metaanalysis indicated that levosimendan was associated with significantly reduced risk of death as compared to the conventional inotropes [20]. A recent review article also illustrated that Levosimendan might be potentially beneficial in reducing mortality risk [21]. However, one recently large trial demonstrated controversial result. The result did not show any survival benefit for levosimendan treatment in patients with septic shock [22].

So we performed a comprehensive systematic review and meta-analysis of randomized clinical trials to assess the effects of levosimendan on mortality in patients with septic shock.

\section{RESULTS}

\section{Literature search}

According to the search strategy, a total of 150 related studies were retrieved. Removing duplicate studies and evaluating the quality of the literatures, ten RCTs (816 participants) were eventually included in the study [17-19, 22-28]. The flow diagram summarizing the process of study selection is shown in Figure 1.

\section{Study characteristics}

The main features of the ten trials included in present study were shown in Table 1 . The publication year ranged from 2005 to 2017. Eight studies had dobutamine as comparator [17-19, 23, 24, 26-28], while one study evaluated levosimendan versus guideline-guided therapy [25], and another one study evaluated levosimendan versus Placebo therapy [22]. All studies administered levosimendan as a 24 hours continuous infusion without bolus. The RCT quality evaluation standard described in the Cochrane Review Handbook was used. The assessments of risk of bias for the included studies were shown in Figures 2 and 3.

\section{Comparative analysis of mortality}

The pooled results from the fixed-effects model combining the risk ratio (RR) for mortality were shown in Figure 4. There was no significant difference in the mortality at the longest follow-up available between the levosimendan group and the standard inotropic therapy group, 165 of 412 in the levosimendan group and 168 of 404 in the control group $[\mathrm{RR}=0.96,95 \% \mathrm{CI}(0.81-1.12)$, $p=0.60]$, and the value of $I^{2}$ index was $0 \%$.

\section{Reliability and conclusiveness of composite outcome result}

We assumed a $40 \%$ control event rate (the control event rate in our meta-analysis for the composite outcome) and a $20 \%$ relative risk reduction (the average relative risk reduction among previous trials) with $80 \%$ power and a 0.05 two sided $\alpha$ to determine the optimal information size. Our calculations indicated that the optimal

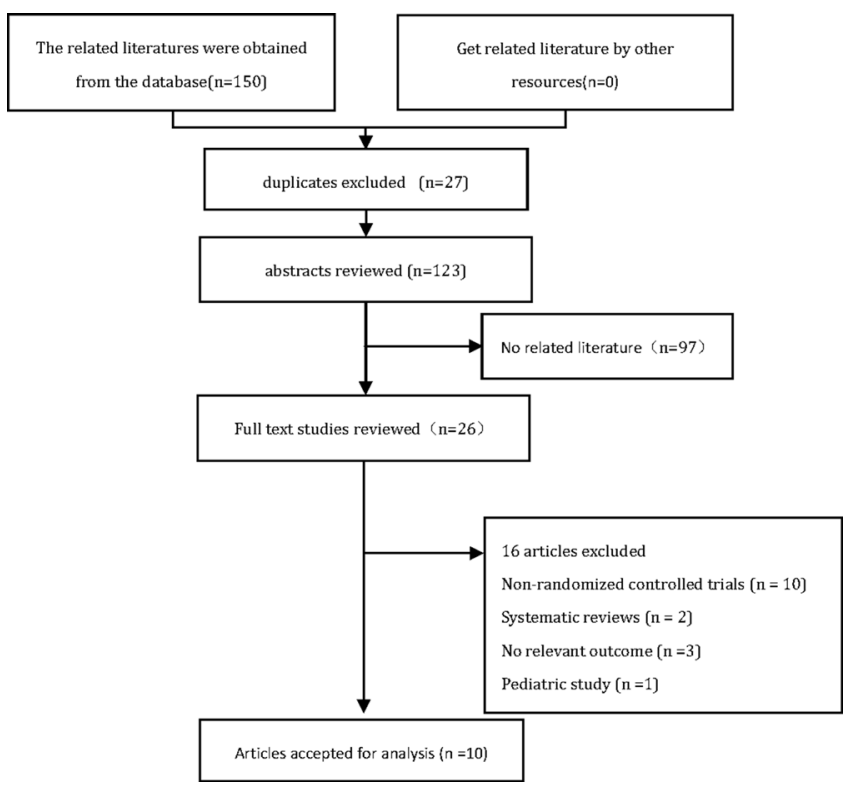

Figure 1: PRISMA flow diagram for trial selection. 
Table 1: The main characteristics of $10 \mathrm{RCTs}$ included in this meta-analysis

\begin{tabular}{|c|c|c|c|c|c|c|c|c|c|c|}
\hline $\begin{array}{l}\text { Study: first } \\
\text { author }\end{array}$ & Year & $\begin{array}{c}\text { Mean age of } \\
\text { participants } \\
\text { levosimendan/ control } \\
\text { (years) }\end{array}$ & Setting & $\begin{array}{c}\text { Levosimendan } \\
\text { Patients }\end{array}$ & $\begin{array}{l}\text { Control } \\
\text { Patients }\end{array}$ & Control & $\begin{array}{l}\text { Assessment of } \\
\text { cardiac function }\end{array}$ & $\begin{array}{c}\text { Levosimendan } \\
\text { Infusion Dose } \\
\mu \mathrm{g} / \mathrm{kg} / \mathrm{min}\end{array}$ & $\begin{array}{l}\text { Dobutamine } \\
\text { Infusion Dose } \\
\mu \mathrm{g} / \mathrm{kg} / \mathrm{min}\end{array}$ & $\begin{array}{l}\text { Lenght of } \\
\text { levosimendan } \\
\text { infusion }\end{array}$ \\
\hline Alhashemi et $\mathrm{al}^{31}$ & 2009 & NR & $\begin{array}{c}\text { Severe } \\
\text { Sepsis or } \\
\text { Septic Shock }\end{array}$ & 21 & 21 & Dobutamine & NR & $0.05-0.2$ & $5-20$ & $24 \mathrm{~h}$ \\
\hline Fang et $\mathrm{al}^{29}$ & 2014 & $61.4 / 61.7$ & Septic Shock & 18 & 18 & Dobutamine & $\begin{array}{l}\text { CI, LVSWI, } \\
\text { LVEDI, LVESI, } \\
\text { LVEF }\end{array}$ & 0.2 & 5 & $24 \mathrm{~h}$ \\
\hline Gordon et $\mathrm{al}^{21}$ & 2016 & $67 / 69$ & septic shock & 258 & 256 & Placebo & $\mathrm{CI}, \mathrm{SV}$ & $\leq 0.2$ & NR & $24 \mathrm{~h}$ \\
\hline Hajje et $\mathrm{al}^{26}$ & 2017 & $61 / 51$ & septic shock & 10 & 10 & Dobutamine & CI & 0.2 & 5 & $24 \mathrm{~h}$ \\
\hline Memis et $\mathrm{al}^{19}$ & 2012 & $54.93 / 56.27$ & Septic Shock & 15 & 15 & Dobutamine & NR & 0.1 & 10 & $24 \mathrm{~h}$ \\
\hline Meng et $\mathrm{al}^{27}$ & 2016 & $55.4 / 50.2$ & septic shock & 19 & 19 & Dobutamine & $\begin{array}{l}\text { CI, LVSWI, } \\
\text { LVEF }\end{array}$ & 0.2 & 5 & $24 \mathrm{~h}$ \\
\hline morelli et al ${ }^{17}$ & 2005 & $61.5 / 62.4$ & Septic Shock & 15 & 13 & Dobutamine & $\begin{array}{l}\text { RAP, PAOP, SI, } \\
\text { CI, LVSWI }\end{array}$ & 0.2 & 5 & $24 \mathrm{~h}$ \\
\hline Morelli et a ${ }^{18}$ & 2010 & $68 / 66$ & Septic Shock & 20 & 20 & Dobutamine & $\begin{array}{l}\text { CI, RAP, PAOP, } \\
\text { LVSWI }\end{array}$ & 0.2 & 5 & $24 \mathrm{~h}$ \\
\hline Torraco et $\mathrm{al}^{28}$ & 2014 & $70 / 68$ & Septic Shock & 13 & 13 & $\begin{array}{l}\text { Standard } \\
\text { Therapy }\end{array}$ & NR & 0.2 & NR & $24 \mathrm{~h}$ \\
\hline Vaitsis et $\mathrm{al}^{30}$ & 2009 & 66.1 & $\begin{array}{c}\text { Severe } \\
\text { Sepsis or } \\
\text { Septic Shock }\end{array}$ & 23 & 19 & Dobutamine & CI, EF & 0.1 & $5-10$ & $24 \mathrm{~h}$ \\
\hline
\end{tabular}

CI cardiac index, LVSWI left ventricular stroke work index, RAP right atrial pressure, PAOP pulmonary artery occlusion pressure, SV stroke volume, SI stroke index, EF ejection fraction, LVEDI left ventricular end-diastolic volume index, LVESI left ventricular end-systolic volume index, NR not report.

information size needed to reliably detect a plausible treatment effect was 1256 patients. Currently, 816 patients were randomly assigned in the trials, not yet up to the size. We constructed the TSA to determine the reliability of the outcomes (Figure 5). Z value of 7 trials which published before 2015, crossed the traditional boundary, but the sequential monitoring boundary had not been crossed and the accumulated amount of information was not up to the optimal information size. These indicated that the evidence may be false positive. Combining the recent trials [22-24], cumulative $\mathrm{Z}$ value of all 10 trials did not cross the traditional boundary and sequential monitoring boundary, similarly the accumulated amount of information was not up to the optimal information size, indicating that the cumulative evidence was unreliable and inconclusive.

\section{Comparative analysis of secondary endpoints}

Seven studies $[17,18,22-24,26,28]$ reported blood lactate which was significantly reduced in the

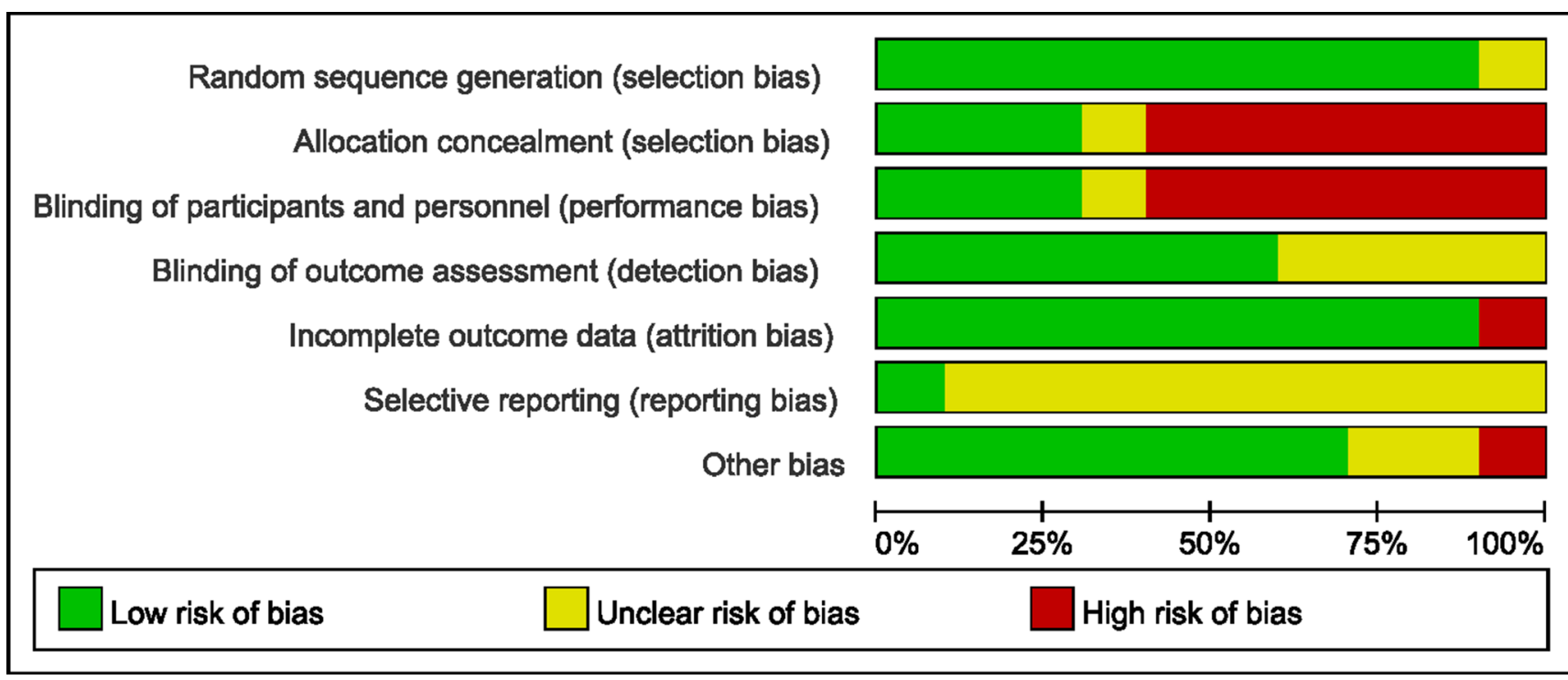

Figure 2: Methodological quality graph: review authors' judgements about each risk of bias item presented as percentages across all included studies. 


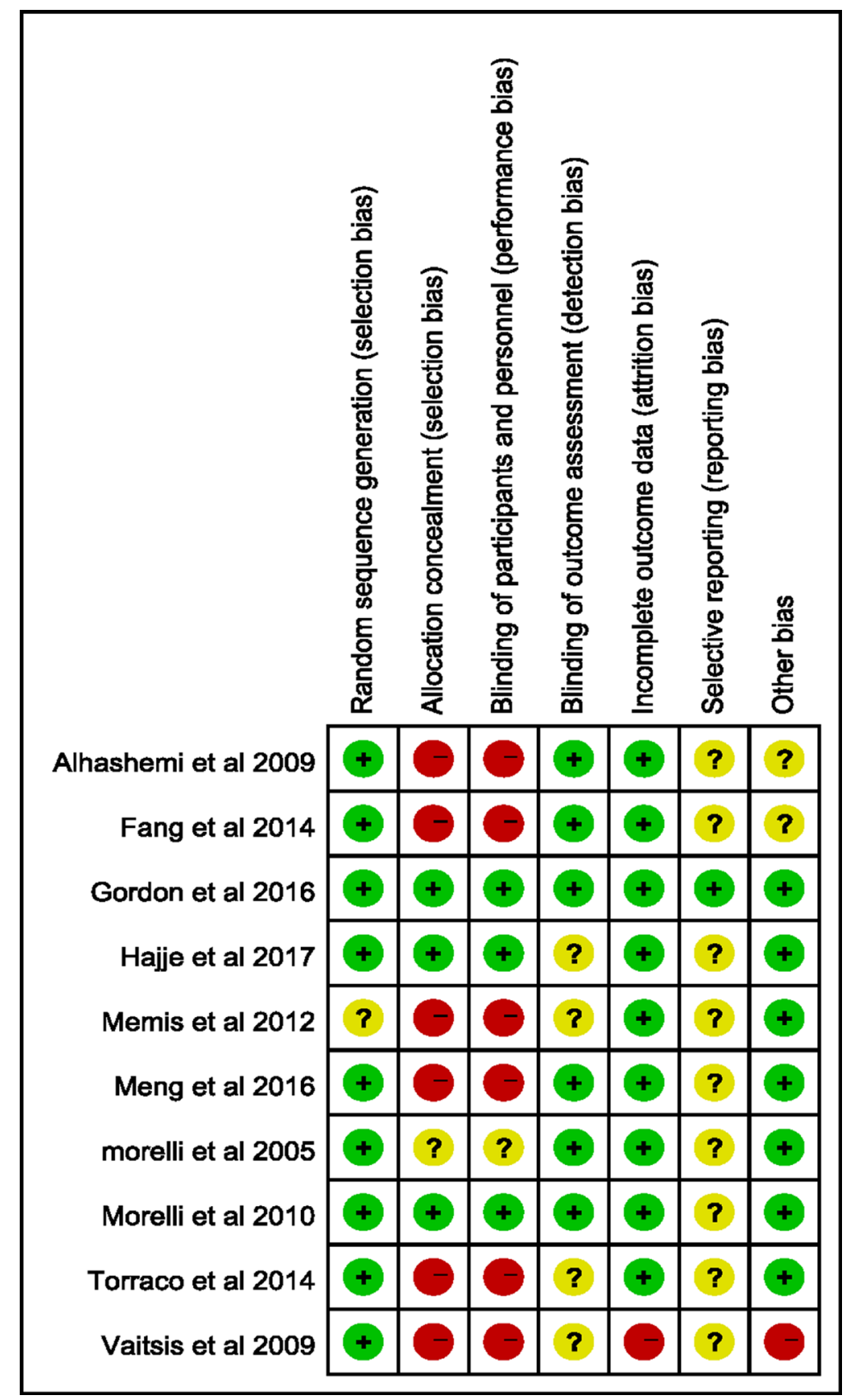

Figure 3: Methodological quality summary: review authors' judgements about each risk of bias item for each included study.

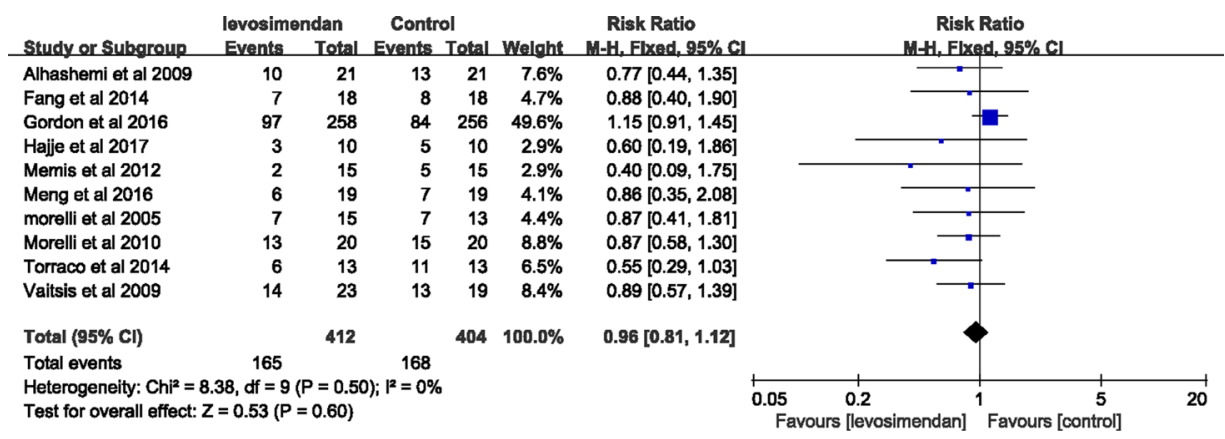

Figure 4: Forest plot for the risk of mortality at longest follow up available. 
levosimendan group (RR: -0.71 , [95\% CI: $-1.36,-0.06], p$ for effect $=0.03)$. There was no difference in MAP [17-19, 22-26] (RR:1.99, [95\% CI:-0.66,4.64], p for effect $=$ 0.14 ), CI [17, 18, 22-24, 26] (RR:0.23, [95\% CI: -0.22 , $0.69], \mathrm{p}$ for effect $=0.32)$, norepinephrine dose $[17,18$, 22-24, 26] (RR:0.00, [95\% CI: $-0.02,0.02]$, p for effect $=$ 0.88 ) and length of ICU stay [18, 19, 22, 24] (RR: -2.67 , [95\% CI: $-6.18,0.85], p$ for effect $=0.14)($ Table 2$)$.

\section{DISCUSSION}

In the present meta-analysis, our findings demonstrated that levosimendan treatment may not reduce mortality in patients with septic shock. However, the LanDeMets sequential monitoring boundary which applied to TSA indicated that the cumulative evidence was unreliable and inconclusive, further studies were necessary to confirm the effect of levosimendan on mortality in patients with septic shock. Furthermore, secondary analyses showed that blood lactate was significantly reduced in the levosimendan group while there was no difference in MAP, CI, norepinephrine dose and length of ICU stay compared to control.

A recent meta-analysis [20] supported the use of levosimendan in patients with sepsis shock significantly improved the overall survival compared with that standard inotropic therapy, but the sample size was obviously too small. Previous research had shown that small studies tended to report larger beneficial effects than large trials, the conclusions of meta-analyses involving small trials may be unreliable [29]. Therefore we constructed the TSA to assess the reliability and conclusiveness of composite outcome result. $Z$ value of 7 trials (i.e., included in the recent metaanalysis [20]), crossed the traditional boundary, but the sequential monitoring boundary had not been crossed. In addition, the accumulated amount of information is not up to the optimal information size, these prompted that the evidence may be false positive. Our meta-analysis which updated the data indicated there was no significant difference in the mortality between the levosimendan group and the standard inotropic therapy group. Regretfully, the cumulative evidence was unreliable and inconclusive.

From a pharmacological viewpoints, levosimendan is an inotropic agent which differs from catecholamines, such as dobutamine. By sensitizing cardiac cell to exist levels of intracellular calcium, an increase in the force of contraction during systole without affecting diastolic relaxation [12]. As levosimendan doesn't increase myocardial oxygen demand, relaxation of the myocardium is not impaired, which may be an additional benefit over catecholamines [30]. In addition, levosimendan has an active metabolite, which has a long half-life of around $80 \mathrm{~h}$, a single 24-hour infusion lasts for almost a week [31], which is long enough to support the majority of patients with septic shock until hemodynamic recovery [32]. Consequently, levosimendan may be an inviting therapy in these patients. Nevertheless, the primary outcome of this study was negative, as well as the most secondary endpoints. Besides, the large randomized controlled trial [22] indicated that levosimendan was associated with a higher risk of supraventricular tachyarrhythmia compared to control and another severe side effect of levosimendan, such as severe vasoplegia that might be difficult to control, should be in attention [21].

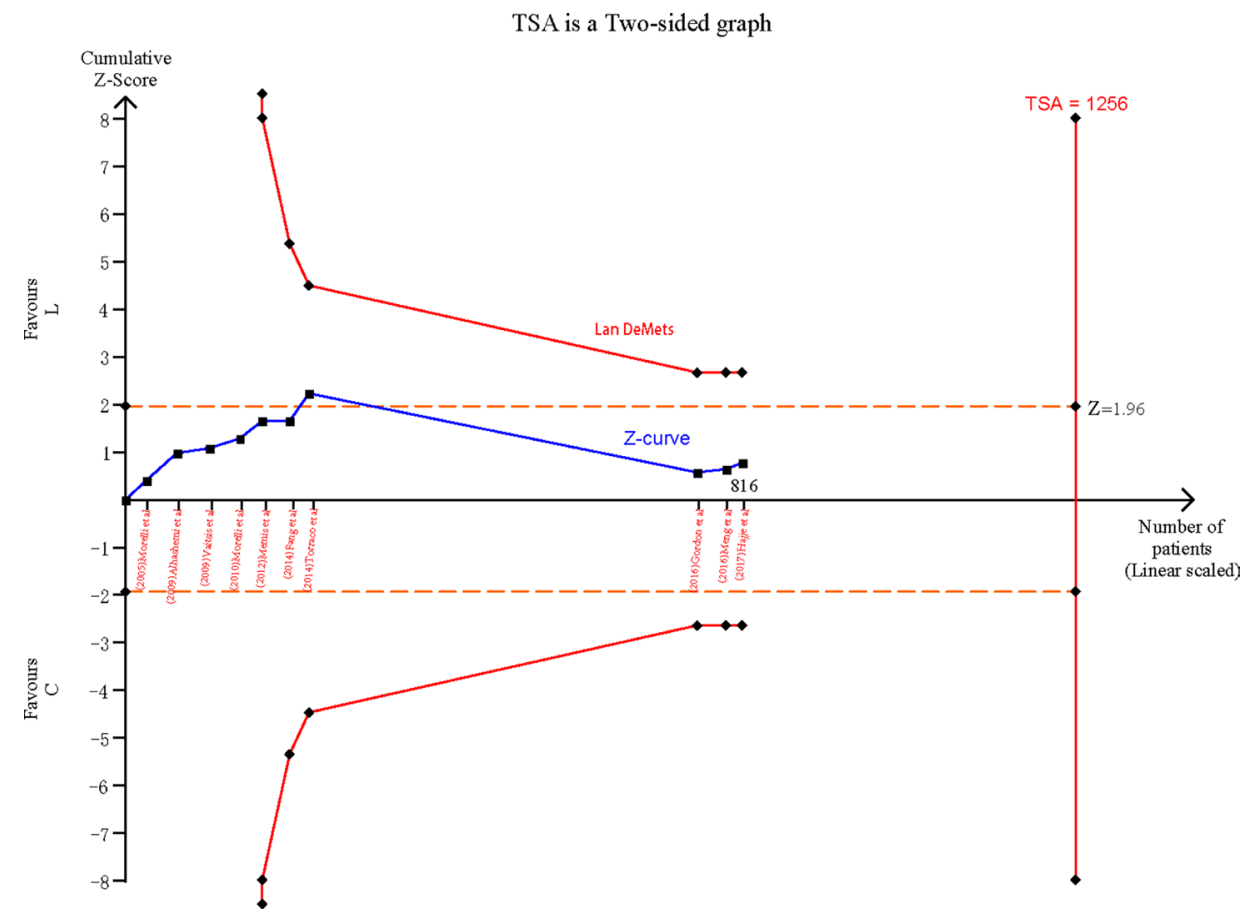

Figure 5: Cumulative meta-analysis assessing the effect of levosimendan on mortality in patients with septic shock. 
Table 2: Secondary endpoints after randomizations

\begin{tabular}{cccccc}
\hline Secondary outcomes & Number of studies & RR (95\% CI) & $\boldsymbol{P}$ (heterogeneity) & $\boldsymbol{I}^{\mathbf{2}}$ (\%) & $\boldsymbol{P}$ (overall effect) \\
\hline $\begin{array}{c}\text { Cardiac index } \\
(\mathrm{L} / \mathrm{min} / \mathrm{m} 2)\end{array}$ & 6 & $0.23[-0.22,0.69]$ & $<0.00001$ & 93 & 0.32 \\
$\begin{array}{c}\text { Mean arterial pressure } \\
(\mathrm{mmHg})\end{array}$ & 8 & $1.99[-0.66,4.64]$ & $<0.00001$ & 93 & 0.14 \\
$\begin{array}{c}\text { Blood lactate (mmol/L) } \\
\quad\end{array}$ & 7 & $-0.71[-1.36,-0.06]$ & $<0.00001$ & 94 & 0.03 \\
$\begin{array}{c}\text { Norepinephrine dose } \\
(\mu \mathrm{gg} / \mathrm{kg} / \mathrm{min})\end{array}$ & 6 & $0.00[-0.02,0.02]$ & 0.91 & 0 & 0.88 \\
$\quad \begin{array}{c}\text { Length of ICU stay } \\
(\text { days })\end{array}$ & 4 & $-2.67[-6.18,0.85]$ & 0.16 & 42 & 0.14 \\
\hline
\end{tabular}

A major strength of our study is that data were from good quality studies. Besides, we assessed mortality which was the most important clinical outcome. Moreover, we used the optimal information size to help to construct the TSA to assess the reliability and conclusiveness of composite outcome result.

Several limitations should be acknowledged as well. First, in addition to the study [22], the rest of the dataset was quite small. Second, the assessment of cardiac function in the study was inconsistent, especially the study [22] which recruited a wide range of patients with sepsis, without requiring a low cardiac output as an enrollment criterion. Third, a comparison of levosimendan with an alternative inotrope was different, eight out of the ten RCTs included in the present study used dobutamine as control inotropic agent [17-19, 23, 24, 26-28]. One study [25] evaluated levosimendan versus guidelineguided therapy, and another one study [22] evaluated levosimendan combined with guideline-guided therapy versus placebo combined with guideline-guided therapy which was different from other trials.

\section{CONCLUSIONS}

Findings from this meta-analysis demonstrated that levosimendan treatment may not reduce mortality in patients with septic shock. The result remains inclusive and further randomized controlled trials were needed to confirm these conclusions.

\section{MATERIALS AND METHODS}

\section{Literature search}

Preferred Reporting Items for Systematic Review and Meta-Analyses (PRISMA) statement was followed [33]. We searched PubMed, EMBASE, Cochrane Library Database updated to March 27, 2017, without language restrictions. By following search terms: "levosimendan", "levosimedan", "Sepsis", "Septicemia", "Septic shock", "randomized clinical trial" and so (Supplementary Table 1). Furthermore, we screened reference lists of obtained publications and reviews for additional eligible studies.

\section{Study selection}

All relevant information in included studies was extracted by one reviewer (B. J. W), and checked for accuracy independently by another reviewer (R. J. C). They screened the titles or abstracts, or both, of the search results and assessed the remaining full-text articles for eligibility. Any uncertainty regarding eligibility was resolved by discussion. Studies were included for our meta-analysis if:(1) the study was conducted in patients with septic shock, (2) the intervention was levosimendan, (3) the outcome of interest was mortality, and(4) the study design was a RCT(i.e., not comments or review); Exclusion criteria: nonintravenous administration of levosimendan, duplicate publications and pediatric studies.

\section{Data extraction}

Two investigators (B. J. W and R. J. C) extracted the following data: name of first author and year of publication, mean age of participants, clinical setting, sample size, control treatment, assessment of cardiac function, levosimendan dose and length (Table 1). The primary endpoint was mortality at the longest follow-up available. The secondary endpoints were cardiac index(CI), mean arterial pressure (MAP), blood lactate, norepinephrine dose and length of ICU stay. If the data were unavailable, we corresponded with the author(s) for the relevant data. 


\section{Quality assessment}

Two reviewers (B. J. W and R. J. C) independently screened the literature and assessed the quality of the literature and cross-checked. The consensus process to resolve disagreements required researchers to discuss the reasoning for their decisions, if it could not be reached, we consulted a third reviewer (Y. Y. G). Methodological quality evaluation was using the RCT quality standard of Cochrane Review, Handbook. We considered each question and classified it as "low," "high," or "unclear", such as selection bias (random sequence generation, allocation concealment), performance bias (blinding of participants and personnel), detection bias (blinding of examiner), attrition bias (loss to follow-up, incomplete outcome data), and selective outcome reporting and other bias [34].

\section{Statistical analysis}

All outcomes were expressed as relative risk (RR), and forest plots were produced to visually assess the RR and corresponding 95\% confidence interval (CI) across studies [35]. The $I^{2}$ and $\chi^{2}$ would be used to express statistical heterogeneity in the meta-analysis. A useful statistic for quantifying heterogeneity is $I^{2}=(\mathrm{Q}-\mathrm{df}) / \mathrm{Q} 100 \%$ where $\mathrm{Q}$ was the chi-squared statistic and df was its degrees of freedom, and its ranges from 0 to $100 \%$. Studies with an $I^{2}$ statistic of $0-25 \%$ were considered to have little heterogeneity, 25-50\% represented low heterogeneity, $50-75 \%$ referred to as moderate estimates, and over $75 \%$ described considerable heterogeneity [36]. We pooled the study-specific estimate using the inverse variance method and a fixed effect model. All statistical analyses were performed using Review Manager (version 5.3 for Windows; the Nordic Cochrane Centre, Copenhagen, Denmark). All statistical tests were 2-sided and $\alpha<0.05$ was considered statistically significant level [37].

The estimation of sample size was required by the repeatability principle of clinical trials aiming at the study power in meta-analysis. Therefore the TSA was used to assess the reliability and conclusiveness of the available evidence on levosimendan [38], focusing on the composite outcome of mortality in patients with septic shock. We calculated the sample size (optimal information size) requirement for our meta-analysis, and used this monitoring boundary as a way of determining whether the evidence in our meta-analysis was reliable and conclusive. TSA software we used was from the Copenhagen Trial Unit(http://www.ctu.dk/tsa/).

\section{Abbreviations}

CIs $=$ confidence intervals; $\mathrm{RR}=$ relative risk; $\mathrm{TSA}=$ trial sequential analysis; $\mathrm{RCT}=$ randomized controlled trial; $\mathrm{CI}=$ cardiac index; $\mathrm{MAP}=$ mean arterial pressure; $\mathrm{ICU}=$ intensive care unit.

\section{Author contributions}

Benji Wang and Bihuan Cheng designed the study. Benji Wang and Rujie Chen extracted data. Xianyang Guo and Wenwu Zhang did the statistical analyses. Jianjian $\mathrm{Hu}$ and Yuqiang Gong reviewed the results. Benji Wang and Bihuan Cheng wrote the report. All authors approved the final version of the paper.

\section{ACKNOWLEDGMENTS}

The authors would like to acknowledge the second affiliated hospital and Yuying children's hospital of Wenzhou Medical University for supporting the work in this study.

\section{CONFLICTS OF INTEREST}

The authors declare no conflicts of interest.

\section{FUNDING}

None

\section{REFERENCES}

1. Singer M, Deutschman CS, Seymour CW, Shankar-Hari M, Annane D, Bauer M, Bellomo R, Bernard GR, Chiche JD, Coopersmith CM, Hotchkiss RS, Levy MM, Marshall JC, et al. The Third International Consensus Definitions for Sepsis and Septic Shock (Sepsis-3). JAMA. 2016; 315:801-10. https://doi.org/10.1001/jama.2016.0287.

2. Shankar-Hari M, Phillips GS, Levy ML, Seymour CW, Liu VX, Deutschman CS, Angus DC, Rubenfeld GD, Singer M, Sepsis Definitions Task F. Developing a New Definition and Assessing New Clinical Criteria for Septic Shock: For the Third International Consensus Definitions for Sepsis and Septic Shock (Sepsis-3). JAMA. 2016; 315:775-87. https://doi.org/10.1001/jama.2016.0289.

3. Stevenson EK, Rubenstein AR, Radin GT, Wiener RS, Walkey AJ. Two Decades of Mortality Trends among Patients with Severe Sepsis: A Comparative Meta-analysis. Critical Care Medicine. 2014; 42:625-31.

4. Kaukonen KM, Bailey M, Suzuki S, Pilcher D, Bellomo R. Mortality related to severe sepsis and septic shock among critically ill patients in Australia and New Zealand, 20002012. JAMA. 2014; 311: 1308.

5. Rhodes A, Evans LE, Alhazzani W, Levy MM, Antonelli M, Ferrer R, Kumar A, Sevransky JE, Sprung CL, Nunnally ME, Rochwerg B, Rubenfeld GD, Angus DC, et al. Surviving Sepsis Campaign: International Guidelines for Management of Sepsis and Septic Shock. Intensive Care Med. 2017; 43:304-377.

6. Vieillard-Baron A, Caille V, Charron C, Belliard G, Page B, Jardin F. Actual incidence of global left ventricular 
hypokinesia in adult septic shock. Critical Care Medicine. 2008; 36:1701-6.

7. Parrillo JE. Myocardial depression during septic shock in humans. Critical Care Medicine. 1990; 18:1183-4.

8. Hernandez G, Bruhn A, Luengo C, Regueira T, Kattan E, Fuentealba A, Florez J, Castro R, Aquevedo A, Pairumani R. Effects of dobutamine on systemic, regional and microcirculatory perfusion parameters in septic shock: a randomized, placebo-controlled, double-blind, crossover study. Intensive Care Medicine. 2013; 39:1435-43.

9. Wilkman E, Kaukonen KM, Pettilä V, Kuitunen A, Varpula M. Association between inotrope treatment and 90-day mortality in patients with septic shock. Acta Anaesthesiologica Scandinavica. 2013; 57:431-42.

10. Nieminen MS, Fruhwald S, Heunks LM, Suominen PK, Gordon AC, Kivikko M, Pollesello P. Levosimendan: current data, clinical use and future development. Heart Lung \& Vessels. 2013; 5:227.

11. Papp Z, Csapó K, Pollesello P, Haikala H, Édes I. Pharmacological Mechanisms Contributing to the Clinical Efficacy of Levosimendan. Cardiovascular Therapeutics. $2005 ; 23: 71$.

12. Ukkonen H, Saraste M, Akkila J, Knuuti MJ, Lehikoinen P, Någren K, Lehtonen L, Voipiopulkki LM. Myocardial efficiency during calcium sensitization with levosimendan: a noninvasive study with positron emission tomography and echocardiography in healthy volunteers. Clinical Pharmacology \& Therapeutics. 1997; 61:596-607.

13. Wang Q, Yokoo H, Takashina M, Sakata K, Ohashi W, Abedelzaher LA, Imaizumi T, Sakamoto T, Hattori K, Matsuda N. Anti-Inflammatory Profile of Levosimendan in Cecal Ligation-Induced Septic Mice and in Lipopolysaccharide-Stimulated Macrophages. Critical Care Medicine. 2015; 43:1.

14. Hasslacher J, Bijuklic K, Bertocchi C, Kountchev J, Bellmann R, Dunzendorfer S, Joannidis M. Levosimendan inhibits release of reactive oxygen species in polymorphonuclear leukocytes in vitro and in patients with acute heart failure and septic shock: a prospective observational study. Critical Care. 2011; 15:R166.

15. Parissis JT, Adamopoulos S, Antoniades C, Kostakis G, Rigas A, Kyrzopoulos S, Iliodromitis E, Kremastinos D. Effects of levosimendan on circulating pro-inflammatory cytokines and soluble apoptosis mediators in patients with decompensated advanced heart failure. American Journal of Cardiology. 2004; 93:1309-12.

16. Toit EFD, Genis A, Opie LH, Pollesello P, Lochner A. A role for the RISK pathway and KATP channels in pre- and post- conditioning induced by levosimendan in the isolated guinea pig heart. British Journal of Pharmacology. 2008; 154:41-50.

17. Morelli A, De Castro S, Teboul JL, Singer M, Rocco M, Conti G, De Luca L, Di Angelantonio E, Orecchioni A, Pandian NG, Pietropaoli P. Effects of levosimendan on systemic and regional hemodynamics in septic myocardial depression. Intensive Care Med. 2005; 31:638-44. https:// doi.org/10.1007/s00134-005-2619-z.

18. Morelli A, Donati A, Ertmer C, Rehberg S, Lange M, Orecchioni A, Cecchini V, Landoni G, Pelaia P, Pietropaoli P, Van Aken H, Teboul JL, Ince C, et al. Levosimendan for resuscitating the microcirculation in patients with septic shock: a randomized controlled study. Crit Care. 2010; 14:R232. https://doi.org/10.1186/cc9387.

19. Memiş D, Inal MT, Sut N. The effects of levosimendan vs dobutamine added to dopamine on liver functions assessed with noninvasive liver function monitoring in patients with septic shock. Journal of Critical Care. 2012; 27:318.e1-.e6. https://doi.org/10.1016/j.jcrc.2011.06.008.

20. Zangrillo A, Putzu A, Monaco F, Oriani A, Frau G, De Luca M, Di Tomasso N, Bignami E, Lomivorotov V, Likhvantsev V, Landoni G. Levosimendan reduces mortality in patients with severe sepsis and septic shock: A metaanalysis of randomized trials. J Crit Care. 2015; 30:908-13. https://doi.org/10.1016/j.jcrc.2015.05.017.

21. Zhang Z, Chen K. Vasoactive agents for the treatment of sepsis. Ann Transl Med. 2016; 4.

22. Gordon AC, Perkins GD, Singer M, Mcauley DF, Orme RM, Santhakumaran S, Mason AJ, Cross M, AlBeidh F, Best-Lane J. Levosimendan for the Prevention of Acute Organ Dysfunction in Sepsis. New England Journal of Medicine. 2016.

23. Hajjej Z, Meddeb B, Sellami W, Labbene I, Morelli A, Ferjani M. Effects of Levosimendan on Cellular Metabolic Alterations in Patients with Septic Shock: A Randomized Controlled Pilot Study. Shock. 2017. https://doi. org/10.1097/SHK.0000000000000851.

24. Meng JB, Hu MH, Lai ZZ, Ji CL, Xu XJ, Zhang G, Tian S. Levosimendan Versus Dobutamine in Myocardial Injury Patients with Septic Shock: A Randomized Controlled Trial. Med Sci Monit. 2016; 22:1486-96.

25. Torraco A, Carrozzo R, Piemonte F, Pastore A, Tozzi G, Verrigni D, Assenza M, Orecchioni A, D'Egidio A, Marraffa E, Landoni G, Bertini E, Morelli A. Effects of levosimendan on mitochondrial function in patients with septic shock: a randomized trial. Biochimie. 2014; 166-73.

26. Fang M, Dong S. Effects of levosimendan on hemodynamics and cardiac function in patients with septic shock. Zhonghua Wei Zhong Bing Ji Jiu Yi Xue. 2014; 26:692-6. https://doi.org/10.3760/cma.j.issn.2095-4352.2014.10.002.

27. Vaitsis J, Michalopoulou H, Thomopoulos C, Massias S, Stamatis P. Use of levosimendan in myocardial dysfunction due to sepsis. Critical care (London, England). 2009.

28. Alhashemi JA, Alotaibi QA, Abdullah GM, Shalabi SA. Levosimendan vs dobutamine in septic shock. J Crit Care. 2009; 24:e14-5. https://doi.org/10.1016/j.jcrc.2009.06.006.

29. Zhang $\mathrm{Z}, \mathrm{Xu} \mathrm{X}, \mathrm{Ni} \mathrm{H}$. Small studies may overestimate the effect sizes in critical care meta-analyses: a metaepidemiological study. Crit Care. 2013; 17:R2. https://doi. org/10.1186/cc11919. 
30. Jörgensen K, Bech-Hanssen O, Houltz E, Ricksten SE. Effects of levosimendan on left ventricular relaxation and early filling at maintained preload and afterload conditions after aortic valve replacement for aortic stenosis. 2008; 117:1075-81.

31. Kivikko M, Antila S, Eha J, Lehtonen L, Pentikäinen PJ. Pharmacokinetics of levosimendan and its metabolites during and after a 24-hour continuous infusion in patients with severe heart failure. International Journal of Clinical Pharmacology \& Therapeutics. 2002; 40:465.

32. Gordon AC, Mason AJ, Thirunavukkarasu N, Perkins GD, Cecconi M, Cepkova M, Pogson DG, Aya HD, Anjum A, Frazier GJ. Effect of Early Vasopressin vs Norepinephrine on Kidney Failure in Patients With Septic Shock: The VANISH Randomized Clinical Trial. JAMA. 2016; 316:509.

33. Moher D, Liberati A, Tetzlaff J, Altman DG, Group TP. Preferred Reporting Items for Systematic Reviews and Meta-Analyses: The PRISMA Statement. Revista Española De Nutrición Humana Y Dietética. 2010; 18:889-96.
34. Wu YC, Tsai WC, Tu YK, Yu TY. Comparative effectiveness of non-operative treatments for chronic calcific tendinitis of the shoulder: A systematic review and network metaanalysis of randomized-controlled trials. Archives of Physical Medicine \& Rehabilitation. 2017.

35. Zhang J, Yu KF. What's the Relative Risk?: A Method of Correcting the Odds Ratio in Cohort Studies of Common Outcomes. JAMA. 1998; 280:1690.

36. Dersimonian R, Nan L. Meta-analysis in clinical trials revisited. Contemporary Clinical Trials. 2015; 45:139.

37. Wang J, Xue Y, Thapa S, Wang L, Tang J, Ji K. Relation between Age-Related Macular Degeneration and Cardiovascular Events and Mortality: A Systematic Review and Meta-Analysis. Biomed Research International. 2016; 2016:8212063.

38. Pogue JM, Yusuf S. Cumulating evidence from randomized trials: Utilizing sequential monitoring boundaries for cumulative meta-analysis. 1997; 18:580-93; 661-6. 